\title{
CARCINOMA RENAL METASTÁSICO INTRAOCULAR. CEGUERA UNILATERAL PROGRESIVA COMO FORMA DE PRESENTACIÓN
}

\author{
J.Á. GÓMEZ PASCUAL, M.S. MARTÍNEZ MARTÍN*, R. BONILLA PARRILLA, \\ J. IRIGOYEN DIAAZ**, J.M. DEL ROSAL SAMANIEGO, J. RAMOS TITOS, \\ V. BAENA GONZÁLEZ
}

Servicio de Urología. *Servicio de Anatomía Patológica. **Servicio de Oftalmología. Hospital Regional de Málaga. Complejo Hospitalario Carlos Haya. Málaga.

Actas Urol Esp. 28 (3): 324-326, 2004

\begin{abstract}
RESUMEN
CARCINOMA RENAL METASTÁSICO INTRAOCULAR. CEGUERA UNILATERAL PROGRESIVA COMO FORMA DE PRESENTACIÓN

El carcinoma renal de células claras es el tipo histológico más frecuente (70-80\%) ${ }^{1}$. En el momento del diagnóstico de un carcinoma de células renales (CCR), las metástasis están presentes en aproximadamente un $25-30 \%$ de los pacientes. La localización ocular es extremadamente rara.
\end{abstract}

PALABRAS CLAVE: Metástasis. Carcinoma renal. Tratamiento.

\begin{abstract}
INTRAOCULAR METASTATIC RENAL CARCINOMA PRESENTING AS PROGRESSIVE UNILATERAL BLINDNESS

Clear cell renal carcinoma is the most common histological type, representing $70-80 \%$ of all renal carcinomas ${ }^{1}$. Metastases are already present in about $25-30 \%$ of patients at the time of diagnosis of renal cell carcinoma. Ocular metastasis is extremely rare.
\end{abstract}

KEY WORDS: Metastases. Renal carcinoma. Treatment.

$\mathrm{E}^{1}$ carcinoma renal de células claras es el tipo histológico más frecuente $(70-80 \%)^{1}$. En el momento del diagnóstico de un carcinoma de células renales (CCR), las metástasis están presentes en aproximadamente un $25-30 \%$ de los pacientes. La diseminación suele ser hematógena y el pulmón es el órgano diana más frecuentemente afectado seguido de hueso, hígado y cerebro. La localización ocular es extremadamente rara.

\section{CASO CLÍnICO}

Presentamos el caso de un varón de 71 años de edad que acudió al Servicio de Urgencias por dolor en fosa renal izquierda de 1 mes de evolución, astenia generalizada y hematuria macroscópica aparecida en la última semana. Así mismo presentaba dolor ocular derecho y pérdida progresiva de visión de 2 meses de evolución. Como antecedentes personales el paciente presentaba una insuficiencia renal crónica avanzada secundaria a 
nefroangiosclerosis de dos años de evolución, hiperuricemia, hipertensión arterial esencial, diabetes mellitus tipo II y enfermedad pulmonar obstructiva crónica.

En la exploración física destacamos obesidad, cierto grado de palidez de piel y mucosas, con puño-percusión renal negativa, no-palpación de masas ni organomegalias ni edemas en miembros inferiores Con respecto a la analítica realizada destaca bioquímica sanguínea con una creatinina de $3,60 \mathrm{mg} / \mathrm{dl}$, urea de $130 \mathrm{mg} / \mathrm{dl}$ y glucemia de $174 \mathrm{mg} / \mathrm{dl}$. Resto de parámetros analíticos dentro de la normalidad.

Las pruebas de imagen que se realizaron incluyeron en primer lugar una ecografía abdominal que reveló una masa en el riñón izquierdo mal definida de aspecto heterogéneo con áreas hipo e hiperecogénicas sin poder diferenciar la ecoestructura renal. Se practicó una resonancia nuclear magnética abdominal (Fig. 1) que mostró la existencia de una masa en polo superior de riñón izquierdo de $10 \mathrm{~cm}$, compatible con hipernefroma, con imágenes sugestivas de hemorragia y necrosis intratumoral. La retinoscopia o fondo de ojo (Fig. 2) reveló tumoración a nivel de coroides junto a desprendimiento exudativo de retina, hallazgos confirmados con ecografia ocular y

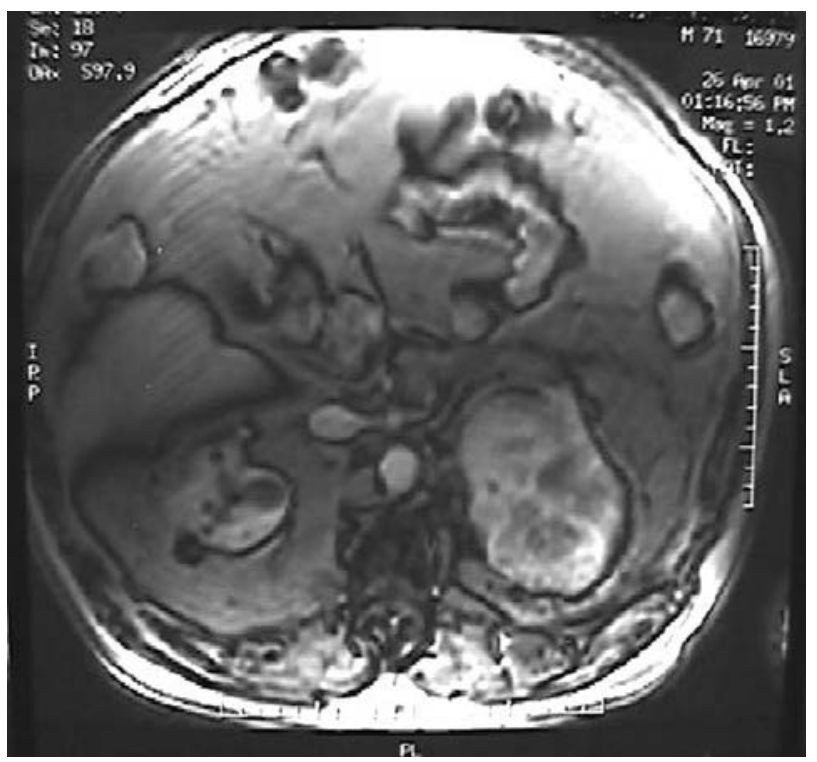

FIGURA 1. Imagen de resonancia nuclear magnética abdomino-pélvica en T2 que muestra la existencia de una masa renal izquierda compatible con hipernefroma, con imágenes sugestivas de hemorragia y necrosis intratumoral. resonancia nuclear magnética cráneo-orbitaria que no evidenció extensión cerebral. La radiografia de tórax y la gammagrafía ósea fueron negativas. Con el diagnóstico preoperatorio de hipernefroma renal izquierdo con probable metástasis a nivel coroideo, se realizó nefrectomía radical izquierda confirmando el estudio anatomopatológico un carcinoma renal de células claras, grado 3 de Furhman, que no infiltraba tejido adiposo perirrenal pero sí el borde de resección de una vena con trombosis tumoral de la misma. Estadio pT3b de la clasificación TNM. A las 8 semanas se sometió a enucleación del globo ocular derecho y tras estudio de la pieza se confirmó metástasis ocular de origen renal con desprendimiento de retina secundario (Fig. 3).

\section{DISCUSIÓN}

Las metástasis oculares de carcinoma de células renales (CCR) son muy poco frecuentes; se han descrito seis casos a nivel coroideo $^{2,4}$, tres en iris ${ }^{3}$ y uno en glándula lacrimal. Pueden preceder al diagnóstico de CCR o aparecer años después. Este intervalo entre la enfermedad ocular y sistémica puede ser tan largo que dificulte la relación diagnóstica entre la metástasis y el tumor primario. En cuatro de los pacientes con metástasis en coroides, dicha tumoración fue la manifestación inicial del CCR. La forma de presentación de este caso es extremadamente rara ya que la pérdida progresiva unilateral de visión fue el primer síntoma que apareció en este paciente, siendo necesario una retinografia que informó de la existencia de una masa a nivel coroideo de probable origen metastásico dados los antecedentes.

El pronóstico de pacientes con CCR metastásico no tratado es malo, con una supervivencia media del $5 \%$ a los tres años. El tratamiento de la metástasis renal es muy difícil por su resistencia tanto a radioterapia como a quimioterapia. Experiencias con inmunoterapia han mostrado una respuesta completa en pacientes seleccionados y un aumento del indice de supervivencia a los tres años de hasta el $31 \%$. En pacientes con metástasis oculares, sobre todo en iris, se ha realizado tratamiento conservador siempre que no exista dolor ocular persistente o glaucoma secundario $^{4}$. El Interferón-alfa usado como único fármaco ha aumentado la supervivencia en un $20 \%{ }^{2}$. 


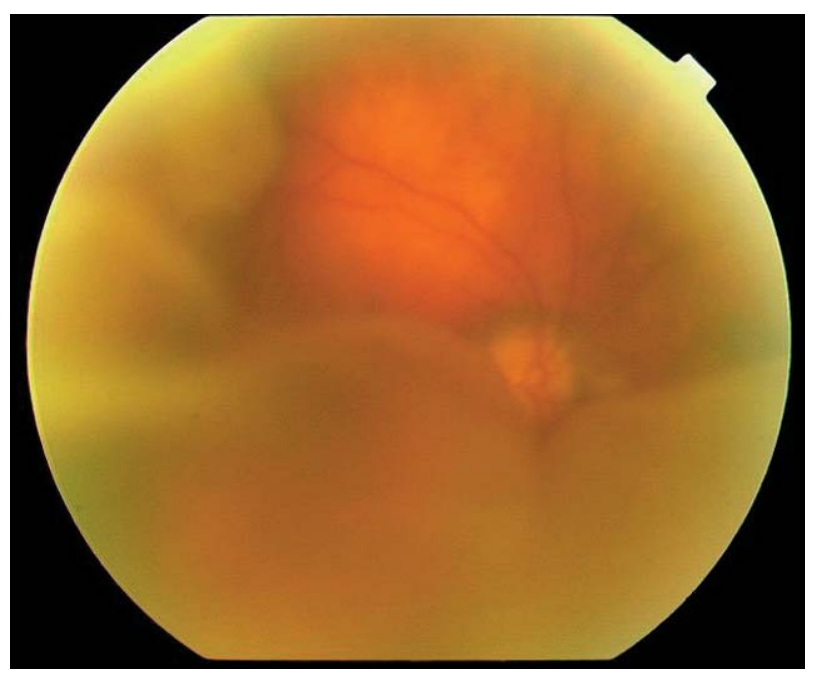

FIGURA 2. Fondo de ojo: imagen de masa retiniana compatible con desprendimiento exudativo de retina. En suelo aparece tumoración con efecto masa compatible con metástasis ocular como primera posibilidad.

Más recientemente se han evaluado los efectos de Interferón-alfa usado en combinación con Interleukina 2 y fluoruracilo o con ácido 13-cisretinoico.

\section{REFERENCIAS}

1. MEVORACH RA, SEGAL AJ, TERSEGNO ME, FRANK IN.: Renal cell carcinoma: incidental diagnosis and natural history: review of 235 cases. Urol 1992 jun; 39 (6): 519-522.

2. ALLAN J. PANTUCK, AMNON ZISMAN, ARIE S. BELLDEGRUN.: The changing natural history of renal cell carcinoma. J Urol 2001; 166: 1611-1623.

3. IKEDA T, SATO K, TOKUYAMA T.: Interferon alfa therapy against metastatic iris tumor of renal cell carcinoma. Arch Ophtalmol 2000 jun; 118 (6): 846847.

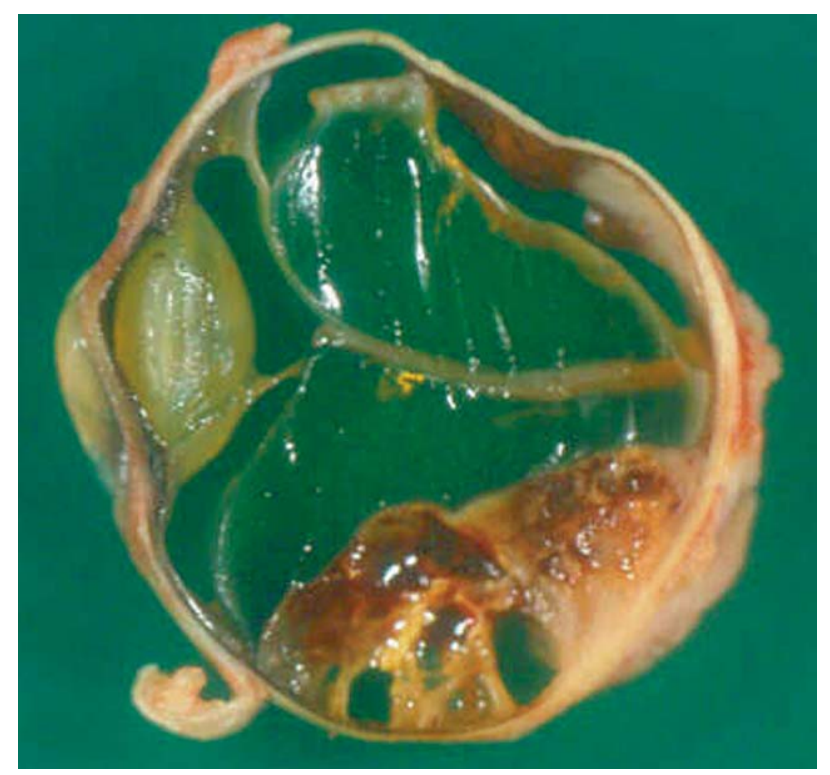

FIGURA 3. Pieza de enucleación ocular de $2,5 \mathrm{~cm}$ de diámetro máximo. Al corte presenta una zona retiniana desprendida y ocupada por una tumoración de $1,5 \times 0,7 \mathrm{~cm}$ de dimensiones máximas y con áreas de aspecto hemático. El examen microscópico observó un carcinoma renal de células claras con desprendimiento de retina secundario.

4. HOLBACH L, CHEVEZ P, SNYDER WB, FONT RL.: Unsuspected renal cell carcinoma metastatic to the choroid nine years after nephrectomy. Am J Ophtalmol 1990; 110 (4): 441-443.

Dr. J.Á. Gómez Pascual

Servicio de Urología.

Hospital Infanta Elena

Ctra. Sevilla-Huelva, s/n

21080 Huelva

(Trabajo recibido el 21 julio de 2003) 